\title{
Inhibition of phosphatidylcholine and chitin biosynthesis in Pyricularia oryzae, Botrytis fabae and Fusarium graminearum by edifenphos
}

\author{
Peter R. Binks, ${ }^{1}$ Geoffrey D. Robson, ${ }^{1}$ Michael W. Goosey ${ }^{2}$ and Anthony P. J. Trinci ${ }^{1 *}$ \\ ${ }^{1}$ Microbiology Group, Department of Cell and Structural Biology, School of Biological Sciences, University of \\ Manchester, Manchester M13 9PT, UK \\ ${ }^{2}$ Shell Research Ltd, Sittingbourne, Kent ME9 $8 A G, U K$
}

(Received 20 November 1992; accepted 28 January 1993)

\begin{abstract}
Colony growth of the fungi Pyricularia oryzae, Botrytis fabae and Fusarium graminearum was reduced by $\mathbf{5 0} \%$ $\left(E D_{50}\right)$ by edifenphos concentrations of 7, 25 and $190 \mu \mathrm{M}$ respectively; the phosphatidylcholine (PC) content of biomass of $P$. oryzae, $B$. fabae, and $F$. graminearum harvested from fungicide-containing-cultures was reduced by $50 \%$ by 6,95 and $350 \mu \mathrm{M}$-edifenphos respectively. By contrast, the activities of membrane-bound chitin synthase preparations isolated from the three fungi were approximately equally sensitive to edifenphos. A direct relationship was observed between PC contents of biomass grown in the presence of ediphenphos and in vivo rates of chitin synthesis (biomass incubated with $\left.{ }^{3} \mathrm{H}\right] \mathrm{GlcNAc}$ in the absence of fungicide). Membrane-bound chitin synthase preparations from $P$. oryzae grown in medium containing 3 or $6 \mu \mathrm{M}$-edifenphos had, at the same fungicide concentration, a lower rate of in vivo chitin synthesis than preparations isolated from biomass grown in the absence of edifenphos. Membrane-bound chitin synthase preparations from $P$. oryzae grown in the presence and absence of $6 \mu$ M-edifenphos had the same $K_{\mathrm{m}}$ values for the substrate (UDP- $\left[{ }^{14} \mathrm{C}\right]$ GlcNAc) but different $V_{\max }$ values. The results suggest that chitin synthesis is inhibited directly by non-competitive inhibition of chitin synthase activity, and indirectly following inhibition of $\mathrm{PC}$ biosynthesis. $P$. oryzae is very sensitive to edifenphos because inhibition of PC biosynthesis occurs at very low fungicide concentrations, and therefore in this fungus inhibition of PC biosynthesis probably represents the primary mode of action of the fungicide.
\end{abstract}

\section{Introduction}

Edifenphos (Hinosan; $O$-ethyl $S, S$-diphenylphosphorodithioate) was marketed by Bayer AG in 1968 to control Pyricularia oryzae on rice (Scheinpflug \& Jung, 1968). Maeda et al. (1970) reported that the related organophosphorus fungicide iprobenfos (Kitazin-P) inhibited incorporation of $\left[{ }^{14} \mathrm{C}\right]$-glucosamine into the cell walls of $P$. oryzae and they suggested that the fungicide inhibited chitin synthesis either directly, by inhibiting chitin synthase (EC 2.4.1.16), or indirectly, by altering membrane permeability.

De Waard (1974) found that concentrations of edifenphos and iprobenfos 5-10 times above their $\mathrm{ED}_{50}$ values for mycelial growth were required to inhibit incorporation of $\left[{ }^{14} \mathrm{C}\right]$ glucosamine by $P$. oryzae; $\mathrm{ED}_{50}$ is

*Author for correspondence. Tel. (061) 275 3893; fax (061) 2755656 .

Abbreviations: PC, phosphatidylcholine; $\left[{ }^{14} \mathrm{C}\right] \mathrm{GlcNAc}$, UDP- $N$ acetyl-D- $\left[{ }^{14} \mathrm{C}\right]$ glucosamine; $\left[{ }^{3} \mathrm{H}\right]$ GlcNAc, $N$-acetyl-D- $\left[{ }^{3} \mathrm{H}\right]$ glucosamine. the fungicide concentration which reduces fungal growth or enzyme activity by $50 \%$ compared with the control values. Craig \& Peberdy (1983a) and Leighton et al. (1981) reported that iprobenfos inhibited the in vitro activity of chitin synthase from Aspergillus nidulans and Phycomyces sp., but Brillinger (1979) found that Coprinus cinereus chitin synthase was not inhibited by iprobenfos, and De Waard (1974) reported that Pythium ultimum, an Oomycete fungus with walls containing cellulose but not chitin, was inhibited by both edifenphos and iprobenfos. Thus, there are conflicting reports about the effects of organophosphorus fungicides on chitin synthesis.

Similarly, although edifenphos and iprobenfos increased the membrane permeability of $P$. oryzae (De Waard, 1974), iprobenfos had no effect on the membrane permeability of $A$. nidulans (Craig \& Peberdy, 1983a). There are also contradictory reports of the effects of edifenphos and iprobenfos on phosphatidylcholine (PC) synthesis. For example, Akatsuka et al. (1977), Kodama et al. (1979) and Ross \& Brady (1985) reported that 
organophosphorus fungicides inhibited PC synthesis, but Craig \& Peberdy (1983b) found that iprobenfos did not affect the PC content of $A$. nidulans. Uncertainty about the mode of action of organophosphorus fungicides is further increased by reports that edifenphos inhibited cutinase activity in Colletotrichum gloeosporioides (Dickman et al., 1983) and Fusarium solani (Sisler, 1986).

Binks et al. (1991) showed that edifenphos had a direct inhibitory effect on chitin synthase activity in $F$. graminearum, and suggested that high concentrations $(250 \mu \mathrm{M})$ of the fungicide also affected chitin synthase activity indirectly by altering the phospholipid composition of the membrane. In this paper we relate the relative sensitivity of three fungi to edifenphos to effects of the fungicide on (a) PC content of the membrane and subsequent indirect inhibition of chitin synthase, and $(b)$ direct inhibition of chitin synthase activity by noncompetitive inhibition.

\section{Methods}

Organisms and media. Pyricularia oryzae cav. was obtained from Shell Research, Sittingbourne, Kent; Fusarium graminearum Schwabe strain A 3/5 was obtained from Mr T. W. Naylor, Marlow Foods, Billingham; and Botrytis fabae Sardiña was obtained from the Culture Collection of the Department of Cell and Structural Biology (Univ. Manchester). Fungi were grown on the defined medium of Vogel (1956) but with glucose $\left(10 \mathrm{~g}^{-1}\right)$ as carbon source instead of sucrose. Vogel's mineral salts solution was prepared at $\times 50$ final concentration, sterilized by membrane ( $0.22 \mu \mathrm{m}$ pore diam., Whatman) filtration, and added to the glucose solution, which had previously been sterilized by autoclaving at $121^{\circ} \mathrm{C}$ for $15 \mathrm{~min}$. When necessary, Vogel's medium was solidified with agar ( $15 \mathrm{~g}^{-1}$; Taiyo technical grade, Davis Gelatine). For production of spores for inocula, $P$. oryzae was grown on malt extract agar (Oxoid) and the other fungi were grown on modified Vogel's agar medium.

Chemicals. Hinosan (edifenphos; $O$-ethyl-S,S-diphenylphosphorothioate) was kindly provided by Imperial Chemical Industry, Jealott's Hill Research Station, Bracknell, UK. UDP- $N$-acetyl-D- $\left[{ }^{14} \mathrm{C}\right]$ glucosamine $\left(\left[{ }^{14} \mathrm{C}\right] \mathrm{GlcNAc}\right)\left[272 \mathrm{mCi} \mathrm{mmol}^{-1}\left(10 \cdot 1 \mathrm{GBq} \mathrm{mmol}^{-1}\right)\right]$ and $\mathrm{N}$ acetyl-D- $\left[{ }^{3} \mathrm{H}\right]$ glucosamine $\left(\left[{ }^{3} \mathrm{H}\right] \mathrm{GlcNAc}\right) \quad\left[5.79 \mathrm{Ci} \mathrm{mmol}^{-1} \quad(214 \mathrm{GBq}\right.$ $\left.\mathrm{mmol}^{-1}\right)$ ] were obtained from Amersham. Other chemicals were of Analar grade and, unless stated otherwise, were obtained from $\mathrm{BDH}$.

Cultural conditions. Because $P$. oryzae and B. fabae aggregate when grown in shake-flask culture, the Petri dish method of Cohen (1973) was used to grow these fungi in liquid culture; they were grown in $10 \mathrm{ml}$ volumes of liquid modified Vogel's medium (with or without edifenphos) dispensed in 9-cm-diam. plastic Petri dishes containing $1 \mathrm{ml}$ volumes of $0.001 \%(\mathrm{v} / \mathrm{v})$ Tween 80 (a surfactant which ensured that the medium covered the bottom of the Petri dish). The cultures were inoculated [to give a final spore concentration of about $10^{6}$ spores (ml medium $)^{-1}$ ] with $1 \mathrm{ml}$ volumes of spore suspensions of $P$. oryzae or $B$. fabae. Tween $80(0.1 \%$, w/v; Sigma) was used to harvest spores from 21 to 28 -d-old Petri dish cultures and spores were separated from mycelial biomass by filtering them through one layer of sterile lens tissue (Whatman). Growth (followed by measuring the decrease in the glucose concentration in the medium) in these liquid cultures was exponential until the carbon source was exhausted (results not shown).
F. graminearum was grown in $50 \mathrm{ml}$ volumes in $250 \mathrm{ml}$ Nephlos flasks (Trinci, 1972). Each flask was inoculated with $1 \mathrm{ml}$ of a suspension of macroconidia [giving a final concentration of about $5 \times 10^{4}$ macroconidia $\left(\mathrm{ml} \mathrm{medium}^{-1}\right)$ ] in distilled water, prepared by harvesting macroconidia from 7 to 10-d-old cultures grown on agar medium. The flasks were incubated on a rotary shaker (with a throw of $2.5 \mathrm{~cm}$ ) at 200 r.p.m.

The fungi were grown in the presence and absence of edifenphos and exponential phase biomass $(39 \mathrm{~h}$ and $24 \mathrm{~h}$ after inoculation for stationary liquid and shake flask cultures respectively) was harvested on muslin. All cultures were grown at $25^{\circ} \mathrm{C}$.

Measurement of colony radial growth rate. Colonies were grown in $9 \mathrm{~cm}$ Petri dishes containing $20 \mathrm{ml}$ volumes of solidified medium and inoculated with 4-5 $\mathrm{mm}$ diam. plugs taken from the margin of 7 to 21-d-old colonies. Colony radial growth rates $\left(K_{\mathrm{r}}\right)$ were determined as described by Robson et al. (1988) and $\mathrm{ED}_{50}$ values (the edifenphos concentration at which $K_{\mathrm{r}}$ was reduced by $50 \%$ ) were estimated from plots of $K_{\mathrm{r}}$ against $\log$ fungicide concentration in the medium.

Incorporation of $\left[{ }^{3} H\right]$ GlcNAc by mycelia. Biomass from exponential phase cultures grown in the presence and absence of edifenphos was washed with two $25 \mathrm{ml}$ volumes of modified Vogel's medium and incubated at $25^{\circ} \mathrm{C}$ in $25 \mathrm{ml}$ of modified Vogel's medium containing $\left[{ }^{3} \mathrm{H}\right] \mathrm{GIcNAc}\left[0.08 \mu \mathrm{Ci} \mathrm{m}^{-1}\left(3 \mathrm{kBq} \mathrm{m}^{-1}\right)\right]$ in the presence and absence of edifenphos. Control cultures were treated with $5 \%(\mathrm{v} / \mathrm{v})$ trichloroacetic acid (TCA), prior to being suspended in modified Vogel's medium containing $\left[{ }^{3} \mathrm{H}\right]$ GlcNAc. All treatments were incubated at $25^{\circ} \mathrm{C}$ for $30 \mathrm{~min}$ on a rotary shaker $(200$ r.p.m.). Growth of the test cultures was then stopped by addition of TCA to give a final concentration of $5 \%(\mathrm{v} / \mathrm{v})$. Four replicate $2 \mathrm{ml}$ samples were taken from each flask, filtered through Whatman no. 1 filter papers, and washed with three $2 \mathrm{ml}$ volumes of distilled water. The biomass and filters were then added to scintillation vials containing $4 \mathrm{ml}$ volumes of scintillation fluid (Optiphase Hisafe) and counted using a Packard Tricarb 1500 liquid scintillation analyser. The residual culture in each flask or Petri dish was used for dry weight determinations.

Activity of membrane-bound chitin synthase. Membrane-bound chitin synthase was extracted from exponential phase cultures using the method of Vermeulen \& Wessels (1983) and a modification of the method of Raevan (1981) was used to assay chitin synthase activity as described previously (Binks et al., 1991).

Glucose and $P C$ determinations. The concentration of glucose in stationary liquid cultures was measured using a Reflocheck reflectance photometer (Boehringer Mannheim). For PC analyses, lipids were extracted from fungal biomass harvested from late exponential phase cultures following the procedure of Angus \& Lester (1972). The lipid extract was dried in a rotary evaporator at $45^{\circ} \mathrm{C}$ and glycerophospholipids extracted from the lipid residue three times with $2 \mathrm{ml}$ volumes of chloroform/methanol $(2: 1, \mathrm{v} / \mathrm{v})$. The chloroform/ methanol extracts from each sample were combined, transferred to glass vials, dried under a stream of $\mathrm{CO}_{2}$ and stored at $-20^{\circ} \mathrm{C}$.

Total concentration of phosphorus in the lipid extract was determined as described previously (Robson et al., 1989) and the PC content was determined by the enzymic method of Takayama et al. (1977).

\section{Results}

\section{Effects of edifenphos on colony radial growth rate}

Following a preliminary survey of 28 species of fungi (Binks, 1991), P. oryzae, B. fabae and $F$. graminearum were selected as fungi representative of groups which 


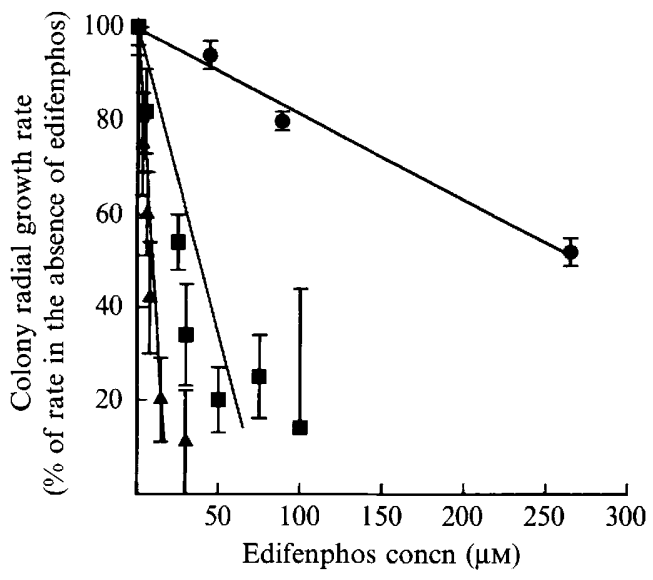

Fig. 1. Effect of various concentrations of edifenphos on the colony radial growth rate of $F$. graminearum $(\mathbf{O}), B$. fabae $(\mathbf{\square})$ and $P$. oryzae $(\boldsymbol{\Delta})$. Colony radial growth rates are expressed as a percentage of the control (absence of edifenphos). Each result is the mean $( \pm \mathrm{SE})$ of six replicates.

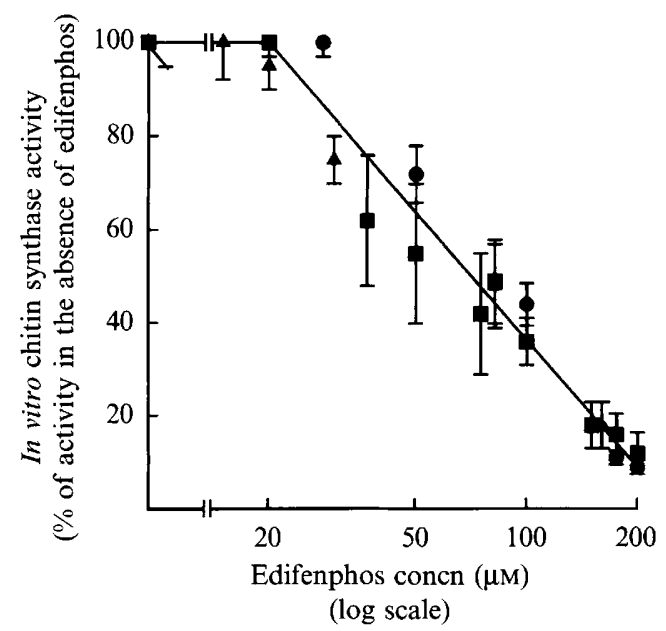

Fig. 2. Effect of edifenphos on the activity of membrane-bound chitin synthase preparations isolated from exponential phase cultures of $P$. oryzae $(\boldsymbol{\Lambda})$, B. fabae $(\boldsymbol{\square})$ and $F$. graminearum $(\boldsymbol{)})$ grown at $25^{\circ} \mathrm{C}$ in modified Vogel's medium. Chitin synthase activity in the presence of edifenphos is expressed as a percentage of that in its absence. Each result is the mean $( \pm \mathrm{SE})$ of four replicates.

were $(a)$ very sensitive, $(b)$ sensitive and $(c)$ slightly sensitive to edifenphos, respectively. The concentrations of edifenphos which reduced the colony radial growth rates $\left(K_{\mathrm{r}}\right)$ of $P$. oryzae, $B$. fabae and $F$. graminearum by $50 \%$ were 7,25 and $190 \mu \mathrm{M}$ respectively (Fig. 1).

\section{Effect of edifenphos on the activity of membrane-bound chitin synthase}

Fig. 2 shows the inhibitory effect of edifenphos on the activity of membrane-bound chitin synthase preparations isolated from exponential phase biomass of

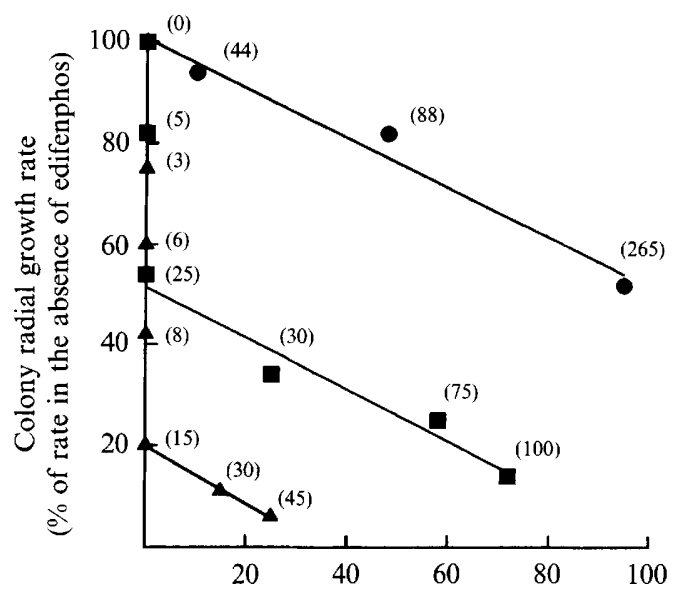

Percentage inhibition of in vitro chitin synthase

Fig. 3. Relationship between the colony radial growth rate of $F$. graminearum $(\boldsymbol{\Delta})$, B. fabae $(\boldsymbol{\square})$ and $P$. oryzae $(\boldsymbol{\Delta})$ and the in vitro chitin synthase activity at various concentrations of edifenphos (shown in parentheses, $\mu \mathrm{M})$. Colony radial growth rate is expressed as a percentage of the control value (absence of edifenphos) and the chitin synthase activity as the percentage reduction compared to the control (absence of edifenphos).

$P$. oryzae, B. fabae and $F$. graminearum grown in the absence of fungicide. At concentrations up to about $20 \mu \mathrm{M}$, edifenphos did not inhibit the activity of the membrane-bound chitin synthase preparations from the three fungi tested. However, at higher concentrations of the fungicide, the chitin synthase activity of all three preparations decreased with the log of edifenphos concentration ( $r=-0.92$ for the combined data). For each membrane preparation, edifenphos caused noncompetitive inhibition of chitin synthase activity with a dissociation constant $\left(K_{\mathrm{i}}\right)$ of the enzyme-inhibitor complex of about $50 \mu \mathrm{m}$ (results not shown).

\section{Relationship between colony radial growth rate and the in vitro and in vivo chitin synthase activity}

When percentage inhibition of colony radial growth rates of the three fungi were correlated with the percentage inhibition of in vitro chitin synthase at various edifenphos concentrations, three different patterns emerged (Fig. 3). For F. graminearum, a decrease in the colony radial growth rate was directly correlated with a decrease in the inhibition of in vitro chitin synthase activity. However, with edifenphos concentrations of up to $15 \mu \mathrm{M}$ ( $P$. oryzae) and $25 \mu \mathrm{M}$ (B. fabae), there was an initial decrease in the colony radial growth rate of $B$. fabae and $P$. oryzae without any inhibition of in vitro chitin synthesis. At higher concentrations, decreases in the colony radial growth rate of all three fungi were associated with a decline in in vitro chitin synthesis. In 


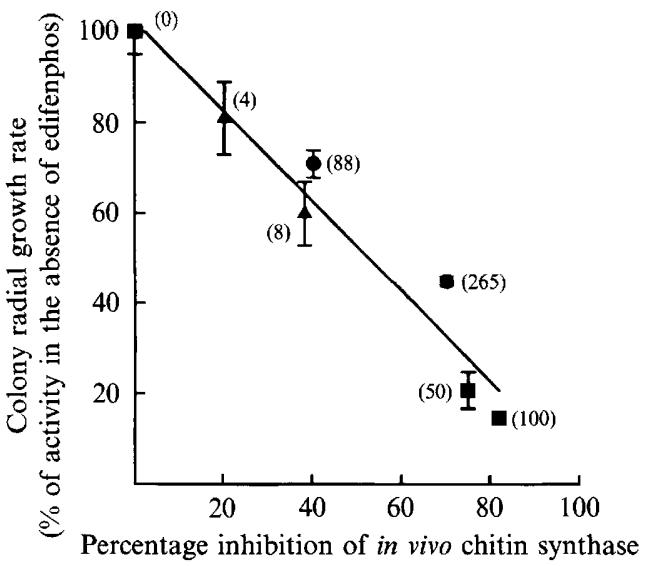

Fig. 4. Relationship between the colony radial growth of $F$. graminearum $(\mathbf{O}), B$. fabae $(\boldsymbol{\square})$ and $P$. oryzae $(\mathbf{\Delta})$ and the in vivo chitin synthase activity at various concentrations of edifenphos (shown in parentheses, $\mu \mathrm{M}$ ). Colony radial growth rate is expressed as a percentage of the control value (absence of edifenphos) and the chitin synthase activity as the percentage reduction compared to the control (absence of edifenphos). Each result is the mean $( \pm \mathrm{SE})$ of four replicates.

Table 1. PC content of $P$. oryzae, $B$. fabae and $F$. graminearum grown in the presence and absence of edifenphos

Liquid cultures grown at $25^{\circ} \mathrm{C}$ in stationary $(P$. oryzae and $B$. fabae) or shake-flask ( $F$. graminearum) liquid cultures were harvested during the exponential phase; the phospholipids present in the biomass were extracted and PC measured by the enzyme assay. PC is expressed as a percentage of the total phospholipid content of the biomass. Each result is the mean $( \pm \mathrm{SE})$ of four replicates. For each species, values with the same superscript $(a-c)$ are not significantly different $(P>0 \cdot 05)$.

\begin{tabular}{lcc}
\hline \hline & $\begin{array}{c}\text { Edifenphos concn } \\
\text { in } \\
\text { culture medium } \\
(\mu \mathrm{M})\end{array}$ & $\begin{array}{c}\text { PC } \\
\text { content } \\
(\% \text { of } \\
\text { phospholipid } \\
\text { content of } \\
\text { biomass })\end{array}$ \\
\hline Prganism & 0 & $54 \cdot 7 \pm 2^{a}$ \\
& 3 & $32 \cdot 5 \pm 2^{b}$ \\
B. fabae & 6 & $27 \cdot 7 \pm 1^{c}$ \\
& 0 & $42 \cdot 2 \pm 4^{a}$ \\
F. graminearum & 5 & $31 \cdot 8 \pm 1^{* b}$ \\
& 50 & $31 \cdot 0 \pm 9^{b}$ \\
& 80 & $23 \cdot 2 \pm 2^{c}$ \\
& 0 & $56 \cdot 2 \pm 3^{a}$ \\
& 40 & $47 \cdot 0 \pm 7^{b}$ \\
\hline \hline
\end{tabular}

* Determined by the method of Takayama et al. (1977).

contrast, the percentage inhibition of colony radial growth rates of $F$. graminearum, $B$. fabae and $P$. oryzae were highly correlated ( $r=-0.97$ for combined data) with the inhibition of in vivo chitin synthase activity by edifenphos (Fig. 4).

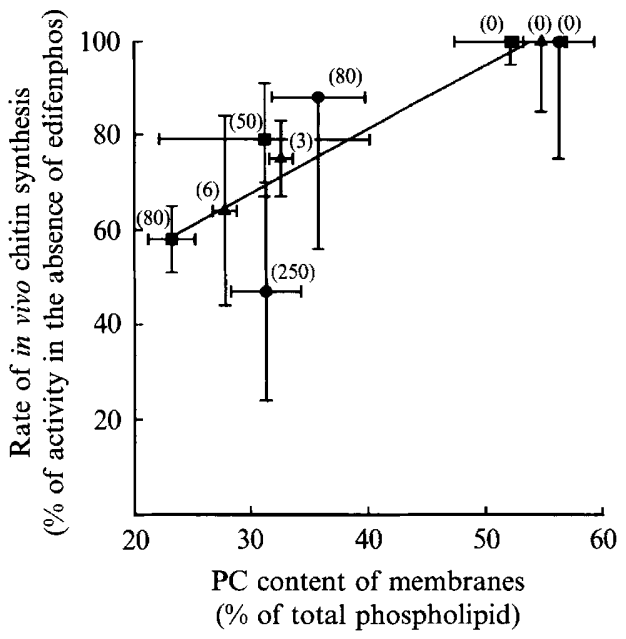

Fig. 5. Relationship between PC content of P. oryzae $(\boldsymbol{\Delta})$, B. fabae $(\boldsymbol{\square})$ and $F$. graminearum $(\bigcirc)$ from exponential phase cultures grown at $25^{\circ} \mathrm{C}$ in modified Vogel's medium in the presence and absence of edifenphos, and the activity of membrane-bound chitin synthase preparations isolated from these same cultures. PC content is expressed as a percentage of the total phospholipid content of the biomass and each result is the mean $( \pm S E)$ of four replicates. The figures in parentheses give the edifenphos concentration $(\mu \mathrm{M})$ in the growth medium.

Effect of edifenphos on the PC content and relationship between $P C$ content and the in vivo rate of chitin synthase

Edifenphos reduced the PC content of all three fungi (Table 1); a $50 \%$ reduction in the $\mathrm{PC}$ content of $P$. oryzae, B. fabae and $F$. graminearum was caused by edifenphos concentrations of 6,95 and $350 \mu \mathrm{M}$ respectively. A direct relationship $(r=0.89)$ was observed between the PC content of biomass grown in the presence of fungicide and the rate of in vivo chitin synthesis of biomass incubated in the absence of fungicide (Fig. 5).

Effect of edifenphos on the rate of in vivo chitin synthesis of $P$. oryzae and B. fabae grown in the presence and absence of fungicide and then incubated in $\left[{ }^{3} \mathrm{H}\right] \mathrm{GlcNAc}$ medium in the presence and absence of fungicide

Compared with the control (biomass grown in the absence of fungicide, washed and then incubated in $\left[{ }^{3} \mathrm{H}\right]$ GlcNAc-medium in the absence of fungicide), no significant $(P>0.05)$ inhibition of in vivo chitin synthesis was observed when $P$. oryzae was grown in medium lacking edifenphos and then incubated in $\left[{ }^{3} \mathrm{H}\right] \mathrm{GlcNAc}-$ media containing 3 or $6 \mu \mathrm{M}$-edifenphos (Table 2). However, when $P$. oryzae was grown in medium containing 3 or $6 \mu \mathrm{M}$-edifenphos (fungicide concentrations known to reduce the PC content of the biomass, Table 1), washed and then incubated in $\left[{ }^{3} \mathrm{H}\right]$ GlcNAc- 
Table 2. Effects of edifenphos on chitin synthesis in $P$. oryzae, grown in the presence and absence of fungicide and then incubated in $\left.{ }^{3} \mathrm{H}\right] \mathrm{GlcNAc}$ in the presence and absence of fungicide

Exponential phase biomass was harvested from stationary, liquid cultures grown at $25^{\circ} \mathrm{C}$ in the presence or absence of edifenphos. The biomass was washed and incubated at $25^{\circ} \mathrm{C}$ for $30 \mathrm{~min}$ in medium containing $\left[{ }^{3} \mathrm{H}\right] \mathrm{GlcNAc}$ in the presence or absence of edifenphos. The rate of $\left[{ }^{3} \mathrm{H}\right] \mathrm{GlcNAc}$ incorporation into chitin is expressed as a percentage of the rate $\left[1.5 \mathrm{pmol}\left[{ }^{3} \mathrm{H}\right] \mathrm{GlcNAc} \mathrm{min}^{-1}\right.$ $\left.(\mathrm{g} \text { dry wt})^{-1}\right]$ of control cultures grown and assayed in the absence of fungicide. Each result is the mean $( \pm \mathrm{SE})$ of four replicates. For each fungicide concentration ( 3 or $6 \mu \mathrm{M}$ ), values with the same superscript $(a$ or $b)$ are not significantly different $(P>0.05)$.

\begin{tabular}{|c|c|c|}
\hline $\begin{array}{l}\text { Edifenphos concn } \\
\text { in } \\
\text { growth medium } \\
(\mu \mathrm{M})\end{array}$ & $\begin{array}{c}\text { Edifenphos concn } \\
\text { in the } \\
{\left[{ }^{3} \mathrm{H}\right] \mathrm{GlcNAc}} \\
\text { incubation } \\
\text { medium }(\mu \mathrm{M})\end{array}$ & $\begin{array}{c}\text { Rate of } \\
\text { incorporation of } \\
{\left[{ }^{3} \mathrm{H}\right] \text { GlcNAc }} \\
\text { into chitin } \\
\text { (\% of } \\
\text { control rate) }\end{array}$ \\
\hline 0 & 0 & $100+15^{a}$ \\
\hline 0 & 3 & $98 \pm 11^{a}$ \\
\hline 3 & 0 & $75 \pm 8^{b}$ \\
\hline 3 & 3 & $74 \pm 7^{b}$ \\
\hline 0 & 0 & $100 \pm 11^{a}$ \\
\hline 0 & 6 & $100 \pm 34^{a}$ \\
\hline 6 & 0 & $64 \pm 30^{b}$ \\
\hline 6 & 6 & $62 \pm 17^{b}$ \\
\hline
\end{tabular}

medium lacking fungicide, there was a significant $(P<0.05)$ reduction of in vivo chitin synthesis. This latter inhibition of in vivo chitin synthesis was not increased when the $\left[{ }^{3} \mathrm{H}\right] \mathrm{GlcNAc}$ incubation medium contained the same concentration ( 3 or $6 \mu \mathrm{M}$ ) of edifenphos as that present in the growth medium (Table 2).

Compared with the control (biomass grown in the absence of fungicide, washed and then incubated in $\left[{ }^{3} \mathrm{H}\right] \mathrm{GlcNAc}-\mathrm{medium}$ in the absence of fungicide), there was a significant $(P<0.05)$ inhibition of in vivo chitin synthesis when $B$. fabae was grown in medium lacking edifenphos and then incubated in $\left[{ }^{3} \mathrm{H}\right]$ GlcNAc-media containing 50 or $80 \mu \mathrm{M}$-edinfenphos (Table 3 ). Inhibition of chitin synthesis was also observed when $B$. fabae was grown in medium containing 50 or $80 \mu \mathrm{M}$-edifenphos, washed and then incubated in $\left[{ }^{3} \mathrm{H}\right] \mathrm{GlcNAc}$-medium lacking fungicide. The highest inhibition of in vivo chitin synthesis was observed when $B$. fabae was grown in medium containing fungicide, washed and then incubated in $\left[{ }^{3} \mathrm{H}\right]$ GlcNAc-medium containing fungicide (Table 3 ).

\section{Activity of membrane-bound chitin synthase isolated from $P$. oryzae grown in the presence and absence of edifenphos}

Membrane-bound chitin synthase was isolated from exponential phase biomass of $P$. oryzae grown in the presence and absence of $6 \mu \mathrm{M}$-edifenphos. Lineweaver-
Table 3. Effects of edifenphos on chitin synthesis in $B$. fabae, grown in the presence and absence of fungicide and then incubated in $\left[{ }^{3} \mathrm{H}\right] \mathrm{GlcNAc}$ in the presence and absence of fungicide

Exponential phase biomass was harvested from stationary, liquid cultures grown at $25^{\circ} \mathrm{C}$ in the presence or absence of edifenphos. The biomass was washed and incubated at $25^{\circ} \mathrm{C}$ for $30 \mathrm{~min}$ in medium containing $\left[{ }^{3} \mathrm{H}\right] \mathrm{GlcNAc}$ in the presence or absence of edifenphos. The rate of $\left[{ }^{3} \mathrm{H}\right] \mathrm{GlcN}$ Ac incorporation into chitin is expressed as a percentage of the rate $\left[8.7 \mathrm{pmol}^{3} \mathrm{H}\right] \mathrm{GlcNAc} \mathrm{min}^{-1}$ $\left.(\mathrm{g} \text { dry } \mathrm{wt})^{-1}\right]$ of control cultures grown and assayed in the absence of fungicide. Each result is the mean $( \pm \mathrm{SE})$ of four replicates. For each fungicide concentration figures with the same superscript $(a-c)$ are not significantly different $(P>0.05)$.

\begin{tabular}{|c|c|c|}
\hline $\begin{array}{l}\text { Edifenphos concn } \\
\text { in } \\
\text { growth medium } \\
(\mu \mathrm{M})\end{array}$ & $\begin{array}{c}\text { Edifenphos conen } \\
\text { in the } \\
{\left[{ }^{3} \mathrm{H}\right] \mathrm{GlcNAc}} \\
\text { incubation } \\
\text { medium }(\mu \mathrm{M})\end{array}$ & $\begin{array}{c}\text { Rate of } \\
\text { incorporation of } \\
{\left[{ }^{3} \mathrm{H}\right] \text { GlcNAc }} \\
\text { into chitin } \\
\text { (\% of } \\
\text { control rate) }\end{array}$ \\
\hline 0 & 0 & $100 \pm 5^{a}$ \\
\hline 0 & 50 & $88 \pm 12^{a}$ \\
\hline 50 & 0 & $79 \pm 12^{a}$ \\
\hline 50 & 50 & $30 \pm 7^{b}$ \\
\hline 0 & 0 & $100 \pm 15^{a}$ \\
\hline 0 & 80 & $45 \pm 7^{b}$ \\
\hline 80 & 0 & $58 \pm 7^{b}$ \\
\hline 80 & 80 & $18 \pm 4^{c}$ \\
\hline
\end{tabular}

Burk plots gave reaction velocities for these enzyme preparations of $5.6 \times 10^{-5} \mathrm{nmol} \mathrm{UDP-GlcNAc} \mathrm{min}^{-1}(\mathrm{mg}$ protein $)^{-1}$ for the membrane-bound chitin synthase preparation from biomass growth in the absence of edifenphos, and $3.2 \times 10^{-5} \mathrm{nmol}$ UDP-GlcNAc $\mathrm{min}^{-1}$ $(\mathrm{mg} \text { protein })^{-1}$ for preparations from biomass grown in $6 \mu \mathrm{M}$-edifenphos. However, growth of $P$. oryzae in $6 \mu \mathrm{M}$ edifenphos did not alter the apparent $K_{\mathrm{m}}(3 \mu \mathrm{M})$ of the membrane-bound chitin synthase preparations (results not shown).

\section{Discussion}

In this study, we examined the effects of edifenphos on $F$. graminearum, B. fabae and $P$. oryzae, which have different sensitivities to edifenphos (Fig. 1). Previous reports have suggested that chitin synthesis is the target of edifenphos and the related organophosphorus fungicide iprobenfos. However, conflicting views have emerged as to whether these fungicides act directly on chitin synthase or indirectly by the inhibition of PC biosynthesis (Maeda et al., 1970; De Waard et al., 1974; Brillinger, 1979; Kodama et al., 1979, 1980; Craig \& Peberdy, $1983 a, b$ ). Chitin synthase preparations from a number of fungi have been shown to be activated by PC (Duran \& Cabib, 1978; Vermeulen \& Wessels, 1983; Montgomery \& Gooday, 1985; Binks et al., 1990). Previously, we have shown that edifenphos inhibits 
chitin synthase from $F$. graminearum in a non-competitive manner (Binks et al., 1990) and also inhibits PC biosynthesis, inducing a highly branched phenotype, without affecting specific growth rate (Wiebe et al., 1990). In this study, in vitro chitin synthase preparations from the three fungi were found to be equally sensitive to edifenphos (Fig. 2), showing that differential sensitivity of the fungi to edifenphos was not due to differences in the sensitivity of chitin synthase to the fungicide. When the reduction in colony radial growth rate caused by edifenphos was correlated with the in vitro reduction in chitin synthase activity, a strong negative correlation was observed for F. graminearum. However, for B. fabae and $P$. oryzae, colony radial growth rate was reduced by about $50 \%$ and $20 \%$ of the respective control values before the edifenphos concentration was high enough to directly inhibit in vitro chitin synthase activity. Surprisingly, when the reductions in colony radial growth rates of the three fungi were examined in relation to the reduction in the in vivo chitin synthase activity caused by various concentrations of edifenphos, a strong negative correlation was found (Fig. 4). This suggests that, for the three fungi, the reduction in colony radial growth rate was due to an edifenphos-induced reduction of in vivo chitin synthase activity, but that only for $F$. graminearum was this caused by direct, non-competitive inhibition of chitin synthase. For $B$. fabae and $P$. oryzae, significant reductions of in vivo chitin synthase activity occurred at fungicide concentrations below those which would inhibit chitin synthase directly.

It has been reported that PC biosynthesis is inhibited by edifenphos and iprobenfos (Kodama et al., 1979, 1980; Binks et al., 1990), and we have demonstrated that reduced levels of PC in a choline-requiring strain of Aspergillus nidulans (choA) were correlated with reductions in (a) the rate of in vivo chitin synthase, $(b)$ colony radial growth rate, and $(c)$ hyphal growth unit length (Binks et al., 1991). When the effects of edifenphos on $F$. graminearum, $B$. fabae and $P$. oryzae were examined, PC levels were found to be reduced but at markedly different fungicide concentrations (Table 1). In this respect, $P$. oryzae was the most sensitive to edifenphos followed by $B$. fabae with $F$. graminearum the least sensitive, suggesting that the sensitivities of the colony radial growth rates of the three fungi to edifenphos may be due to a differential sensitivity to inhibition of PC biosynthesis. This view is supported by the positive correlation observed between the PC content of biomass of the three fungi grown in different concentrations of edifenphos and the in vivo chitin synthase activities of membrane preparations from these three fungi (Fig. 5). The mechanism by which PC modulates the activity of chitin synthase is unknown; however, a kinetic study of chitin synthase activity in a membrane preparation from $P$. oryzae grown in the presence (reduced PC content of the biomass) or absence of edifenphos revealed that the reduction in chitin synthase activity was due to a reduced $V_{\max }$ rather than an altered $K_{\mathrm{m}}$ (results not shown).

In $F$. graminearum, we have previously shown that inhibition in colony radial growth rate by edifenphos is initially due to direct non-competitive inhibition of chitin synthase with no reduction in PC; only at edifenphos concentrations of about $250 \mu \mathrm{M}$ and above is a reduction in PC observed with additional inhibition of chitin synthase (Binks et al., 1990, Table 1). In the moderately sensitive fungus $B$. fabae, reductions in colony radial growth rate appear to be due to a combination of both direct inhibition of chitin synthase activity and an indirect inhibition of this enzyme due to a reduction in the PC content of the membrane (Table 2). However, in the highly sensitive fungus $P$. oryzae, inhibition of chitin synthase occurs by a reduction in the PC content of the membrane rather than by direct inhibition of the enzyme (Table 3).

In summary, the organophosphorus fungicide edifenphos has been shown to inhibit chitin synthase both directly by non-competitive inhibition and indirectly by inhibiting PC biosynthesis (this reduces the PC content of the membrane and lowers the $V_{\max }$ of the enzyme). Differential sensitivity of the three fungi to edifenphos is due to the different concentrations of edifenphos required to inhibit PC biosynthesis in these organisms. The basis of this difference is unknown but may be due to either $(a)$ differences in the sensitivity of methyltransferase enzymes involved in PC biosynthesis to edifenphos, or $(b)$ differences in the uptake of edifenphos.

The induction of colonial (highly branched) phenotypes in $F$. graminearum, $B$. fabae and $P$. oryzae by edifenphos further implicates chitin synthase as playing an important role in the regulation of branching in filamentous fungi. Previously, it has been shown that in Phycomyces blakesleeanus (Martinez-Cadena \& RuizHerrera, 1987) and F. graminearum (G. D. Robson, unpublished observation), chitin synthase activity may be modulated by the calcium regulatory binding protein calmodulin, and that inhibition of calmodulin by various antagonists induces a colonial phenotype in $F$. graminearum (Robson et al., 1991). These observations, together with the dependence of hyphal branching on chitin synthase activity suggest branch pattern development may be modulated by factors which influence intracellular $\mathrm{Ca}^{2+}$ levels.

\section{References}

Akatsuka, T., Kodama, O. \& Yameda, H. (1977). A novel mode of action of kitazin P in Pyricularia oryzae. Agricultural and Biological Chemistry 41, 2111-2112. 
Angus, W. W. \& Lester, R. L. (1972). Turnover of inositol and phosphorus containing lipids in Saccharomyces cerevisiae; extracellular accumulation of glycerophosphatidylinositol derived from phosphatidylinositol. Archives of Biochemistry and Biophysics 151, 483-495.

BINKs, P. R. (1991). The effect of edifenphos on chitin biosynthesis and growth of fungi. $\mathrm{PhD}$ thesis, University of Manchester, UK.

Binks, P. R., Robson, G. D., Goosey, M. W., Humphreys, A. M. \& TRINCI, A. P. J. (1990). Chitin synthesis in Fusarium graminearum and its inhibition by edifenphos (Hinosan). Journal of General Microbiology 137, 615-620.

Binks, P. R., Robson, G. D., Goosey, M. W. \& Trinci, A. P. J. (1991). Relationships between phosphatidylcholine content, chitin synthesis, growth and morphology of Aspergillus nidulans choC. FEMS Microbiology Letters 83, 159-164.

BRILliNGER, G. V. (1979). Metabolic products of micro-organisms 181. Chitin synthase from fungi, a test model for substances with insecticidal properties. Archives of Microbiology 121, 71-74.

CoHEN, B. L. (1973). Growth of Aspergillus nidulans in a thin liquid layer. Journal of General Microbiology 76, 277-282.

Craig, G. D. \& Peberdy, J. F. (1983a). The mode of action of S-benzyl $O, O$-diisopropylphosphorothioate and dichloran on Aspergillus nidulans. Pesticide Science 14, 17-24.

Craig, G. D. \& Peberdy, J. F. (1983b). The effect of $S$-benzyl $O, O$ diisopropylphosphorothioate (IBP) and dichloran on the total lipid, sterol and phospholipids in Aspergillus nidulans. FEMS Microbiology Letters 18, 11-14.

DE WAARD, M. A. (1974). Mechanisms of action of the organophosphorus fungicide Pyrazophos. $\mathrm{PhD}$ thesis, Mededelingen Landbouwhogeschool Wageningen. Wageningen: H. Veenman \& Zonen BV.

Dickman, M. B., Patil, S. S. \& Kolattudy, P. E. (1983). Effects of organophosphorus pesticides on cutinase activity and infection of papayas by Colletotrichum gloeosporioides. Phytopathology 73, 1209-1214.

DURAN, A. \& CABIB, E. (1978). Solubilization and partial purification of yeast chitin synthetase. Conformation of the zymogenic nature of the enzyme. Journal of Biological Chemistry 253, 4419-4425.

Kodama, O., Yamada, H. \& AKatsuka, J. (1979). Kitazin P, inhibitor of phosphatidylcholine biosynthesis in Pyricularia oryzae. Agricultural and Biological Chemistry 43, 1719-1725.

Kodama, O., Yamashita, K. \& Akatsuka, J. (1980). Edifenphos, inhibitor of phosphatidylcholine biosynthesis in Pyricularia oryzae. Agricultural and Biological Chemistry 44, 1015-1021.

Leighton, T., Marks, E. \& Leighton, F. (1981). Pesticides: insecticides and fungicides and chitin synthesis inhibitors. Science 213, 905-907.
Maeda, T., Abe, H., Kakiki, K. \& Misato, T. (1970). Studies on the mode of action of organophosphorus fungicide, Kitazin. Part II. Accumulation of an amino sugar derivative from Kitazin-treated mycelia of Pyricularia oryzae. Agricultural and Biological Chemistry 34, 700-709.

Martinez-Cadena, G. \& Ruiz-Herrera, J. (1987). Activation of chitin synthetase from Phycomyces blakesleeanus by calcium and calmodulin. Archives of Microbiology 148, 280-285.

Montgomery, G. W. G. \& Gooday, G. W. (1985). Phospholipidenzyme interactions of chitin synthase of Coprinus cinereus. FEMS Microbiology Letters 27, 29-33.

RaEvan, M. B. J. M. (1981). Biosynthesis of chitin in fungi. PhD thesis, University of Groningen, NL

Robson, G. D., Kuhn, P. J. \& TrincI, A. P. J. (1988). Effects of validamycin $\mathrm{A}$ on the morphology, growth and sporulation of Rhizoctonia cerealis, Fusarium culmorum and other fungi. Journal of General Microbiology 134, 3187-3194.

Robson, G. D., Kunn, P. J. \& Trinci, A. P. J. (1989). Effect of validamycin $\mathrm{A}$ on the inositol content and branching of Rhizoctonia cerealis and other fungi. Journal of General Microbiology 135, 739-750.

Robson, G. D., Wiebe, M. G. \& Trinci, A. P. J. (1991). Involvement of $\mathrm{Ca}^{2+}$ in the regulation of hyphal extension and branching in Fusarium graminearum A3/5. Experimental Mycology 15, 263-272.

Ross, D. C. \& BRADY, V. E. (1985). Organophosphate pesticides and DMSO affect mycelial growth and phosphatidylcholine biosynthesis in an entomopathic fungus. Journal of Entomological Science 20, $287-293$.

ScheinPflug, H. \& Jung, H. F. (1968). Organophosphates for the control of fungal diseases of crops. Pflanzenschutz-Nachrichten 21, 79-91.

SisLER, H. D. (1986). Control of fungal disease by compounds acting as antipenetrants. Crop Protection 5, 306-313.

TakaYama, M., Itoh, S., Nagasaki, T. \& Tanimizu, I. (1977). A new enzymatic method for determination of serum choline containing phospholipids. Clinica Chimica Acta 79, 93-98.

TRINCI, A. P. J. (1972). Culture turbidity as a measure of mould growth. Transactions of the British Mycological Society 58, 467-473.

Vermeulen C. A. \& Wessels, J. G. H. (1983). Evidence for a phospholipid requirement of chitin synthase in Schizophyllum commune. Current Microbiology 8, 67-71.

Vogel, H. J. (1956). A convenient growth medium for Neurospora (Medium N). Microbial Genetics Bulletin 13, 42-44.

Wiebe, M. G., Robson, G. D. \& TrincI, A. P. J. (1990). Edifenphos (Hinosan) reduces hyphal extension, hyphal growth unit length and phosphatidylcholine content of Fusarium graminearum A3/5, but has no effect on specific growth rate. Journal of General Microbiology 136, 979-984. 